\title{
Las élites del poder en México. Una exploración crítica de la literatura entre las décadas de 1970 y 1990
}

\author{
The power elites in Mexico. A critical review of \\ literature produced in Mexico between 1970-1990
}

doi: http://dx.doi.org/10.32870/

espiral.v24i69.4308

\section{Resumen}

El propósito de este trabajo es hacer una exploración crítica de la literatura producida en México entre 1970 y 1990 sobre sus élites políticas y económicas. Se busca conocer las dimensiones analíticas del interés de los investigadores y los marcos teóricos utilizados con un propósito de fondo: saber si en esa literatura se había hecho alguna conexión entre el ejercicio del poder de la clase política, su relación con la clase empresarial y las condiciones socioeconómicas de la sociedad. Se encuentra que esta conexión no fue del interés de los investigadores, excepto desde el paradigma marxista que predominó en la academia hasta los años 70. Al mismo tiempo, esta predominancia motivó que en México no se siguiera el debate que se daba en la academia estadounidense sobre las élites, y fue hacia los años 80 cuando los enfoques neoinstitucionalistas marcaron la senda de la investigación, conduciéndola principalmente hacia la clase empresarial y sus organizaciones. Aun así, la mayor parte los trabajos revisados no se sustentaron en marcos teóricos y metodológicos rigurosos.

Palabras clave: literatura sobre élites, élites políticas y económicas en México, periodo 1970-1990, exploración crítica, clase empresarial.

\author{
Verónica de la Torre Oropeza
}

\begin{abstract}
The purpose of the paper is to make a critical exploration of the literature produced in Mexico between 1970 and 1990 on its political and economic elites. We seek to know the analytic dimensions and the theoretical frameworks employed by the authors. Behind the main object we investigated whether authors had been done any connection between the interaction and exercise of power of the political class and the business class in the literature, with respect to socioeconomic conditions of society. We found that this aspect was not within researchers' interest, although during the predominance of Marxist paradigm in the 70's some analysis were close to the issue. This circumstance made Mexican scholars did not to follow the debate on the elites in the US academy those years. In the 80 's, researchers gave prominence to the business class and its organizations from institutional approaches, nonetheless most of the works were not supported in theoretical and methodological frameworks.
\end{abstract}

Keywords: literature about elites, political and economic elites in Mexico, literature from 70's to 90's, critical exploration, business class.

\footnotetext{
- Postdoctorante en el Centro de Estudios Latinoamericanos de la Facultad de Ciencias Políticas y Sociales, UNAM, México._orodelatorre@hotmail.com Fecha de recepción: 30 de octubre de 20I5. Fecha de aceptación: 24 de enero de 2017.
} 


\section{Introducción}

Este trabajo surge de la relevancia que han cobrado en las dos últimas décadas las élites del poder económico a nivel global y su estrecha relación con las élites del poder político, ya provengan de los principales países capitalistas o de los países ahora nombrados “emergentes". En este marco, era necesario conocer la participación de los académicos mexicanos en el tema, y para ello hubo que remontarse a sus primeros trabajos.

Se encontró que fueron autores principalmente estadounidenses quienes iniciaron las pesquisas sobre el tema en los años 50. En México, esta tarea se emprendió hacia finales de 1960 mediante estudios y ensayos sobre el sistema político y la clase política. ${ }^{1}$ De este modo, el propósito inicial de este trabajo fue conocer los marcos teóricos y las dimensiones analíticas que en esos años eran del interés de los investigadores. Más aún, la intención de fondo de la exploración era saber si los autores consultados habían hecho algún tipo de conexión entre el ejercicio del poder de la élite política, su interacción con la élite económica y los posibles efectos de esta relación en las condiciones socioeconómicas del país.

No obstante, este trabajo no tiene como objetivo abordar, ni siquiera a nivel de hipótesis, las posibles secuelas socioeconómicas de esa relación, sino que plantea el problema para provocar un interés científico de parte de los cientistas sociales afines, en tiempos donde es bastante claro que el modo en que la clase política y su élite ejercen el poder ha sumido al país en una severa crisis económica y social.

I. Si bien los conceptos de élite política, élite económica y élite del poder no son utilizados en la literatura revisada, este trabajo se apoya en la idea de "élites del poder" de Wright C. Mills (1987), para referir tanto al círculo pequeño del poder político como al del poder económico. En convergencia con John Scott, cuando se hace referencia a las "élites" se señala a aquellas involucradas en el ejercicio del poder y en relación con las estructuras de dominación que las constituyen (2008, pp. 5 y ss.). 
Como preámbulo a este trabajo, se destaca que los primeros estudios sobre las élites políticas y militares en México empezaron a hacerse alrededor de los años 50. Fueron académicos estadounidenses quienes vinieron a conocer al país y a entrevistar a miembros de la élite política en funciones o que habían sido parte de esta. Entre estos autores destacan Frank Tannenbaum (1968), de origen austriaco; William P. Tucker (1957); Frank Brandenburg (1964) y Vincent A. Padget (1966). Sus obras se concentran en la denominada "familia revolucionaria" y el sistema político construido por esta. ${ }^{3}$

En las décadas de 1970 y 1980 se realizaron estudios sobre las élites mexicanas mediante métodos empíricos. Un ejemplo de estos trabajos es el de Gruber, et al. (1971), quien entrevistó a ochenta y ocho personajes, miembros viejos y nuevos de la élite política. Otros trabajos importantes fueron los de académicos como Needleman, et al. (1969) y Peter Smith o Robert E. Scott (ambos citados en Suárez, 1991). Acerca del empresariado mexicano, uno de los primeros estudios fue el de Flavia Derossi (1978), así como el de Dale Story (1986).

Entre los años 80 y 90 se encuentran las investigaciones de Roderic Ai Camp (1990, 2006), de Nora Hamilton (1983) y de Juan D. Lindau (1993). Por otra parte, a finales del siglo XX y comienzos del siglo XXI se encuentran los estudios de Miguel Ángel Centeno (1994), Sarah Babb (2001 y 2003), Judith Teichman (1996 y 2001) y Pamela Starr (1999). Estos últimos trabajos se interesan por el grupo de tecnócratas y políticos, por el carácter de las reformas económicas y su estrecho vínculo con las altas esferas empresariales del país

2.Denominación que Frank Brandenburg dio en su libro The Making Modern Mexico, de 1964. Cabe añadir que Brandenburg fue consultor de negocios en México, y antes había sido profesor en la Universidad Nacional, en el Instituto Politécnico Nacional y en la Universidad de las Américas.

3. Francisco Suárez (199I), de la Universidad Autónoma Metropolitana, hizo un análisis de estas obras en Élite, tecnocracia y movilidad política en México. 
y del extranjero. En cuanto a la importancia del cambio ideológico en el periodo del neoliberalismo, Miguel Ángel Centeno (1994) ha aportado mucho respecto al cambio radical implementado por el grupo tecnócrata de élite desde la década de 1980, no sólo en México, sino en América Latina.

En los años 70, bajo el predominio del enfoque marxista, varios académicos mexicanos emprendieron el estudio de las “clases dominantes". Desde este paradigma, se analizó la relación de poder entre clase gobernante y clase dominante, la evolución de su relación, sus acuerdos y pugnas, así como la situación de dependencia económica de México en el sistema capitalista. Desde ese enfoque, se hicieron críticas agudas al modelo de desarrollo dependiente, al modo en que se legitimaba el poder de ambas clases y a las formas de control social que utilizaban.

En México, muchos estudios hechos a conciencia sobre la relación entre el Estado y la burguesía, o el Estado y la clase dominante, se realizaron en este marco intelectual. Los estudios que se citan más abajo representan un aporte en el conocimiento de esa relación y el modelo de desarrollo, aunque dejaron temas pendientes como el efecto de la confluencia de intereses entre la clase gobernante y la clase dominante sobre el resto de la sociedad, aspecto que en gran medida continuó ausente en la literatura de las décadas siguientes.

El estado de los estudios de las élites desde mediados del siglo $\mathrm{XX}$

El debate que desató el libro Las élites del poder del sociólogo Wright Mills en Estados Unidos, publicado en 1956, continuó muchos años después tras la publicación de la obra Who Governs America, del politólogo R. A. Dahl 
(1961), ${ }^{4}$ y posteriormente, a inicios de los años 80, el libro de William Domhoff (1983), Who Rules America Now, continuó el debate, también aportando mucho en términos metodológicos $;{ }^{5}$ puede decirse que la obra de Domhoff es un puente entre las reflexiones de Wright Mills y el análisis de Robert Dahl.

En México, estas discusiones casi no tuvieron repercusión, lo que representaría un aislamiento con la academia anglosajona que no llegaría a zanjarse, entre otras cosas porque en la década de 1980 los enfoques novedosos del corporativismo y el institucionalismo le dieron la vuelta a los análisis marxistas y condujeron las investigaciones a otros intereses. Así, un grupo importante de la academia mexicana se concentró en el estudio de los grupos empresariales, su desarrollo histórico, local y regional, así como en la realización de biografías y entrevistas a personajes de ese ámbito, como Juan Sánchez Navarro. Algunos aspectos que se estudiaban eran la relación de este sector con el poder político, el rol de sus organizaciones, el discurso de sus principales ideólogos, empresarios e industriales, todo esto bajo la nueva arenga de la globalización.

Con base en la exploración de la literatura sobre las élites en la academia anglosajona y en la literatura de la que es objeto este trabajo, se considera que los estudios sobre los grupos de élite del poder en cualquier lugar del mundo necesitan ser analizados bajo sus propios contextos histórico-culturales como condiciones sine qua non. En el caso mexicano, la construcción histórica social y cultural que se desprende del periodo colonial y luego de la Inde-

4. Sin embargo, hay que tener presente el aporte del sociólogo Floyd Hunter, quien en 1953 publicó Community Power Structure. Se puede decir que él renovó el debate sobre las élites y el poder a poco menos de cincuenta años de la escuela italiana. Véanse: los volúmenes de The Sociology of Elites, de John Scott (I990).

5. También los trabajos que Domhoff realizó con su colega Thomas Dye. 
pendencia es la base de la sociedad que se ha forjado hasta llegar al siglo XXI.

En el marco de esta investigación, se entiende por "clase política" al grupo extenso que incluye a todos los sujetos que de modo profesional trabajan en las instituciones estatales de primer orden y en puestos de dirección, es decir, en el gabinete del Ejecutivo, el Congreso y en los primeros cargos de los partidos políticos. Dentro de esta clase hay una élite, la del poder político, que como grupo selecto es el encargado de tomar las decisiones de Estado trascendentales para la sociedad. Por ejemplo, la Secretaría de Programación y Presupuesto, que José López Portillo creó, conformó junto al gabinete de Presidencia, la Secretaría de Hacienda y Crédito Público y el Banco de México una sola estructura de poder hasta el sexenio de Carlos Salinas de Gortari (Rousseau, 1998, p. 339).

Respecto a la clase empresarial, se entiende por esta, principalmente en términos económicos, al número, extenso en todos los niveles, de empresarios, propietarios, agroexportadores y comerciantes. Dentro de esta clase, la élite económica la conforman una o más fracciones que constituyen el círculo pequeño de poderosos empresarios, industriales y banqueros del país con acceso a y representantes en el poder político. Ambas élites, de acuerdo con Wright Mills (1987), son la élite del poder, cuyos intereses se empalman o convergen. En apariencia, las élites están cohesionadas ideológicamente, y luego potencialmente desunidas entre sí y entre sus fracciones cuando se avizoran amenazas a su posición de poder individual o de grupo. ${ }^{6}$ Son relevantes en la medida en que sus acuerdos y decisiones en materia

6. Field y sus colegas han argumentado que a las élites se les puede describir como desunidas, pero consensualmente unificadas, es decir, estructuralmente integradas y unificadas, y como ideológicamente unificadas, que quiere decir estructuralmente integradas tanto a las reglas del juego como en cuestiones políticas (referido en Camp, 2006, p. 26). 
de políticas públicas afectan la vida de millones de personas. Así, por ejemplo, la estructura de poder creada por el Ejecutivo en consonancia con la élite del poder económico ${ }^{7}$ consiguió que en México un proyecto de la envergadura del Tratado de Libre Comercio de América del Norte (TLCAN) saliera adelante.

Como lo han destacado otros estudios, alrededor de estos círculos de poder existen grupos a favor de las élites del poder en turno que inciden e inclusive colaboran en el sostenimiento y legitimación de dicho poder. Este grupo heterogéneo lo conforman intelectuales, académicos, religiosos, líderes de opinión pública, los propios medios de comunicación de mayor influencia dentro de una sociedad y hasta celebridades, como Mills ya había referido en su libro antes citado (1987, pp. 74 y ss.). ${ }^{8}$

En esta misma línea, y en aras de atender no sólo a los agentes o a la estructura para indagar sobre el proceso de reproducción del poder y de las élites que lo ostentan, es necesaria la implicación de las características del régimen político mexicano. ${ }^{9}$ No se trata de una acción de determinación de la estructura sobre los agentes ni de estos sobre las estructuras, sino de una mutua reproducción, ya que la relación histórica que ha existido entre las élites política y económica ha sido de una recíproca tolerancia por medio de pactos, alianzas y búsqueda de legitimación, mediante lo cual ambas clases han reproducido su poder y mantenido

7. Por ejemplo, los intereses corporativos transnacionales que representaba en ese entonces el señor Claudio X. González. Véase:Tirado (2012).

8. Camp (2006) va más allá de lo que investigadores estadounidense anteriores a él hicieron porque incorpora en las élites a líderes religiosos, intelectuales y militares. 9. En el sentido que lo definió O’Donnell: “los patrones, formales e informales, explícitos e implícitos, que determinan los canales de acceso a las principales posiciones de gobierno, las características de los actores que son admitidos y excluidos a tal acceso, los recursos y las estrategias permitidos para lograrlo, y las instituciones a través de las cuales ese acceso ocurre y desde las cuales, una vez logrado, son tomadas las decisiones gubernamentales" (O’Donnell y Schmitter, 1994, p. I 18). 
las estructuras que sostienen hasta hoy los altos niveles de corrupción, de desigualdad y pobreza en gran parte de la sociedad a lo largo de la historia de México. De ahí que en sistemas políticos semiautoritarios como el mexicano, los pactos, explícitos, tácitos o secretos han sido la base de una relación compleja entre ambas élites del poder en la que cada una busca poner a salvo sus intereses, por encima de las mayorías.

\section{Los estudios sobre las élites políticas y económicas} en México

A pesar de que mucha de la literatura producida en México en los años 80 tuvo enfoques institucionalistas, puede considerarse que se pasó por alto la contribución que investigadores estadounidenses hicieron de las élites bajo ese mismo marco. El propio Mills subrayó que las características institucionales de los países son clave para el estudio de las élites y de su ejercicio del poder (1987, p. 17). Posteriormente, William Domhoff (1983) y su colega Thomas R. Dye (Domhoff y Dye, 1987) subrayaron la importancia de las características institucionales y la organización de la sociedad.

Es justo en este punto donde el entusiasmo en México por los enfoques institucionalistas debiera ser más cauto, debido a las características del régimen político que inciden en el funcionamiento de las instituciones. Quienes han estudiado la capacidad de maniobra de las élites del poder en México coinciden en señalar que el desarrollo institucional es deficiente y la estructura de decisiones muy dependiente de vínculos informales y centralizada en unos cuantos.

En este sentido, cabe recordar la apreciación de Camp acerca de México como un "híbrido institucional" (2006, p. 15). En el caso de este país, cobra sentido el análisis del proceso político de Mills, visto este como una lucha por el poder y el prestigio, por posiciones autoritarias dentro

\section{6}


de cada estado y entre estos. Mills se refirió a las grandes instituciones dentro de un Estado como aquellas puertas de acceso al poder y la riqueza (1987, p. 17), y en México la puerta principal ha sido la instancia del Poder Ejecutivo y la del partido vinculado al Estado y al Congreso.

En el caso mexicano, si se piensa en la influencia que el Consejo Mexicano de Hombres de Negocios (CMHN) ha tenido en la política desde su creación, en 1964, entonces tiene sentido pensar en el papel estratégico de uno o pocos individuos, no precisamente en el peso de toda la organización. Aunque algunos aspectos subrayados por Mills y Domhoff para comprender el poder en la sociedad estadounidense no encajan en el contexto mexicano, sobre todo en lo que concierne a la debilidad de las instituciones, esta característica no invalida el argumento de Domhoff de que "la clase gobernante no existiría sin las instituciones, pero estas están imbuidas de valores de clase [y de la élite]" (1983, pp. 217-218).

En México se puede hablar de la élite del poder como un grupo reducido de personas de los ámbitos político o económico que se legitiman entre sí, con valores, ideas e intereses convergentes -no por ello libres de pugnas entre fracciones-, que fungen como los agentes principales dentro de una estructura de poder vertical, jerárquica, cuyas decisiones son trascendentales para el resto de la sociedad.

La crítica a la debilidad institucional en México debería fungir como una alerta para no perder capacidad crítica dentro de enfoques que privilegian la importancia de las instituciones y el diseño institucional, principalmente frente a la maltrecha división de poderes (González Casanova, 1965; Krieger, 1990; Meyer, 1998a y 1998b; Crespo, 1997) que impide la plena autonomía de instituciones como el Legislativo y el Judicial frente al Ejecutivo o de instancias que se presumen autónomas como el Instituto Nacional Electoral (INE) o el Instituto Nacional de Transparencia, 
Acceso a la Información y Protección de Datos Personales (INAI). ${ }^{10} \mathrm{El}$ acceso a las grandes instituciones, como señala Mills, aquellas que son clave para acceder a la riqueza, al prestigio, a los altísimos ingresos, permite aún señalar que las relaciones entre los muy ricos con el Estado son las que determinan las oportunidades de estos individuos para acceder a la riqueza y al poder (1987, p. 17).

En la literatura producida en México, la mayoría de los estudios han atendido el nivel estructural, el corporativo y el político-ideológico casi siempre por separado, mientras que la relación con las clases subordinadas casi ha sido soslayada, excepto en los escasos estudios sobre cultura empresarial, aludidos más adelante.

Lo que sigue a continuación es el resultado de una exploración de la literatura sobre las élites económicas y políticas de México. Se pone el acento en los aspectos en los que se han interesado los investigadores mexicanos y el modo en que abordaron los problemas u objetos de investigación.

Existe consenso entre los académicos mexicanos de los años explorados respecto a la existencia de cuatro momentos en la relación entre empresarios y Estado. El primero es en el Porfiriato; el segundo en el periodo posrevolucionario; el tercero, la ruptura que llega con el fin del modelo desarrollista de sustitución de importaciones; y el cuarto, el de la alianza entre el sector empresarial fuerte y los nuevos tecnócratas mexicanos a partir de la administración de Miguel de la Madrid Hurtado.

El interés de los académicos en las décadas 80 y 90 se enfocó principalmente en conocer el mundo de los grandes empresarios, sus biografías, sus vínculos con el poder político o el Estado, sus organizaciones corporativas, partidos políticos y empresarios, estos últimos como actores colectivos y grupos de presión. 
Todos estos son aspectos que bajo el predominio intelectual marxista en el estudio del poder político y económico se habían dejado de lado. Sin embargo, desde el marxismo no sólo se hicieron análisis agudos que fueron más allá del interés en la estrecha relación entre el Estado y la burguesía, o de la crítica a la subordinación económica de esta región en el sistema capitalista: también pusieron el acento en las características y comportamiento de la clase empresarial y su privilegiada relación con el Estado.

Análisis como los de José Luis Hoyos (1973), Jorge Alonso (1976), Jorge Carrión y Alonso Aguilar (1977) y Julio Labastida (1980) aludieron a problemas que al día de hoy continúan siendo un obstáculo para la democratización de México y para un desarrollo con equidad, tales como la mutua complacencia entre ambas élites y la corrupción que esta genera. Por ejemplo, el estudio de Concheiro, Fragoso y Gutiérrez (1979), a diferencia de otros análisis marxistas, representa un esfuerzo de vinculación de los tres niveles antes referidos, el estructural, el corporativo y el ideológico. Es una crítica que denuesta el conservadurismo de la burguesía y oligarquía mexicana, pero que no recupera el efecto que en términos de poder tienen estos tres niveles sobre la sociedad. De ahí en adelante, la literatura se ha concentrado en uno u otro nivel dentro de un marco de análisis institucionalista.

Entre todo, los trabajos que se hicieron bajo el paradigma del materialismo histórico son los menos si se comparan con la copiosa literatura que sobre los empresarios se empezó a producir desde finales de los 70. Fue desde ese paradigma que se elaboraron trabajos a conciencia en términos teóricos y metodológicos para estudiar, en un contexto como el mexicano, ya fuera a la burguesía o la clase dominante, a la clase gobernante, a la oligarquía, o en términos gramscianos a la hegemonía o dirección de una clase o fracción, o al bloque del poder, según Poulantzas (1998). 
Muchos autores hicieron alusión en alguna parte de sus trabajos a la polarización socioeconómica en México, pero no se detuvieron demasiado en el tema. Por ejemplo, Julio Labastida, a comienzos de los años 70, dejó en el aire lo que pudo ser una pregunta central en su análisis: ¿las características de las clases dominantes aportaban explicación alguna a las peculiaridades del proceso económico y político mexicano? (1980, p. 103). ${ }^{11} \mathrm{Al}$ mismo tiempo, hay que decirlo, el predominio del marxismo en todo ese tiempo condujo a aislarse o a desdeñar el debate en torno a la teoría de las élites que se realizaba en la academia estadounidense principalmente.

Matilde Luna y Cristina Puga (2006) están entre los autores más prolíficos del periodo estudiado. Se puede estar de acuerdo con las autoras en cuanto a que hubo dos momentos clave en el estudio de los empresarios: de 1975 a 1985 y de 1985 a 1992. En la primera década los investigadores se concentraron en conocer a los hombres de empresas, sus intereses, estrategias, su acción colectiva, su conflictiva relación con los Gobiernos. La segunda época de auge de los estudios sobre este sector, que en algunos trabajos es aludido como burguesía, grupo dominante, iniciativa privada o simplemente empresariado, vino con el grupo de trabajo que se constituyó en el Consejo Mexicano de Ciencias Sociales (COMECSO), ${ }^{12}$ en cuyo seno se realizaron varios seminarios y se redactaron bastantes libros.

I I.En su extenso capítulo en el volumen tres del libro colectivo El perfil de México en 1980, Labastida (1980) hace un análisis de la estructura del poder en México donde considera el inicio de las relaciones entre el Estado, su clase gobernante, y la incipiente burguesía en el México posrevolucionario; enlista varias características de ambos grupos y su evolución a partir de 1940.

I2. Con académicos como Matilde Luna, Ricardo Tirado, Cristina Puga, Jacobo Pozas; dentro del grupo de trabajo enmarcado por COMECSO incursionaron académicos en la rama de Historia Económica como Mario Cerutti, Leonor Ludlow, Carlos Marichal, Leticia Gamboa, Carmen Collado, María Eugenia Romero, Elsa Gracido, Mario Trujillo, entre otros. En un principio también participaron Julio Labastida y colaboradores.

\section{0}


Este consejo permitió la incursión de otros campos que en su medida enriquecieron la investigación sobre la clase empresarial, como el de los historiadores de los empresarios. De acuerdo con Luna y Puga (2006, p. 2), de mediados de la década de 1970 a comienzos de 1990 existieron claramente tres ejes de investigación que predominaron en México: el poder económico de las empresas y grupos empresariales, la historia de los hombres de empresa y la de cómo los empresarios intervenían en la política a título individual o vía sus organizaciones. Entre los escasos trabajos con un enfoque sociológico está el de René Millán (1988), que dimensiona a los empresarios en la categoría de actores sociales, como grupos de presión sobre el Estado y como agentes sociales que buscan la penetración ideológica de la sociedad (pp. 31,66 y 194).

En gran parte de la literatura revisada se ha podido observar el predominio de trabajos, si bien altamente empíricos, concentrados en lo que Luna y Puga reconocieron como "núcleos temáticos y de problemas" (2006, p. 1) coyunturales alejados de debates teóricos, sistematización metodológica y con ausencia de entrevistas. Lo anterior debido, en gran parte, a que la mayoría de las investigaciones se dieron en un marco de intensa relación entre el sector empresarial de mayor peso y la elite política en aquellos años.

En esa misma línea, Hernández Romo (2007) argumenta que es raro encontrar investigaciones rigurosamente delineadas dentro de un marco teórico-conceptual y metodológico (pp. 211-235), o bien, como se señaló antes, que dejen entrever que se conoce el debate sobre el ejercicio del poder de las élites. Menos todavía se encuentra en la copiosa literatura de las décadas señaladas una preocupación sociológica por el comportamiento de las élites del poder y la situación de la desigualdad y la pobreza creciente a raíz del modelo 
económico neoliberal. ${ }^{13}$ Dentro de este grupo, Ricardo Tirado (2004, pp. 154 y ss.) es quien se ha enfocado más en la relación entre las élites del poder: en algunos de sus trabajos ha destacado aspectos vinculados con la corrupción en los años 90, ya sea vía tráfico de influencias, de compra de voluntades y otros aspectos que se vivieron, por ejemplo, durante las negociaciones del TLCAN (2004, pp. 335-364).

Por su parte, desde un enfoque liberal, Valdés Ugalde (1997) critica los análisis marxistas de los años 70 y 80. Este autor considera al empresario como sujeto político: es uno de los autores que asiente la pertinencia de atender las características de una evolución -social- concreta, de ahí que señale que el empresario, como un sujeto social y político complejo y heterogéneo, no puede ser reducido a pseudoexplicaciones clasistas o economicistas (1997, p. 35). De ese modo, el autor enfatiza la importancia de los estudios en los que él ha participado con Matilde Luna, Cristina Puga y Ricardo Tirado, entre otros, que en su opinión han sorteado el estrecho alcance del estudio de las organizaciones y su encuadre legal, enfocándose más en las estrategias empresariales de acción política, en la línea de los estudios del neocorporativismo y el neoinstitucionalismo en general (1997, p. 33).

\section{Los estudios sobre la cultura empresarial, o cultura de la productividad}

Hasta lo aquí reseñado pareciera que el presente trabajo se detiene más en la clase empresarial, pero esto no es más

13. Evidentemente, en México ha habido importantes sociólogos, politólogos y economistas, expertos en el Estado mexicano y el sistema político. En ese sentido, desde luego se piensa en Pablo González Casanova, Daniel CosíoVillegas,Arnaldo Córdova, Juan Felipe Leal, entre otros, cuya aportación es mayúscula. Sin embargo, no fue del interés de esos autores escudriñar en el proceso histórico-cultural que ha constituido el poder político, sus agentes, y sus efectos y consecuencias sobre los gobernados.

\section{2}


que el resultado del auge de los nuevos estudios en los años 80 , los cuales, por otra parte, equilibran la falta de atención a la relación entre los empresarios y la clase trabajadora.

En este sentido, otro tema con cierto auge fue el de la cultura empresarial, particularmente la forma de ser del empresario promedio. Marcela Hernández Romo (2004), desde una perspectiva sociológica, se planteó la interrogante de cómo es la cultura empresarial en México y de si a la luz de los cambios estructurales había habido un cambio de mentalidad desde finales de los 80 .

Otros trabajos en este sentido fueron los de Carlos Alba y colaboradores (citados en Alba, 2006, p. 135) y el estudio de Anselmo García, Andrés Hernández y Roberto Wilde (1995), quienes abordaron la cultura de la producción o de la productividad enfocada en las relaciones obrero-empresa. El estudio de Alba se hizo mediante el envío de un cuestionario a cuarenta y cinco directivos de empresas nacionales y extranjeras de países como Alemania, Estados Unidos y Hong Kong, ubicadas en Guadalajara, Monterrey, Chihuahua, Mexicali y León. Los resultados de la encuesta dejaron claro que hay similitudes entre los directivos, pero también demostraban evidentes diferencias de visión empresarial. La visión empresarial de los alemanes y estadounidenses se distingue en mucho de la de los mexicanos, señalan los autores. Las diferencias más evidentes “tienen que ver con el menor interés por parte de las grandes empresas mexicanas en involucrar a su personal en la toma de decisiones, en la propiedad de las mismas a través de la oferta de acciones o en la distribución de los beneficios económicos" (Alba, 2006, p. 135). En el terreno de la responsabilidad social de las empresas en México, en las entrevistas que Roderic Camp hizo, el investigador examinó que el significado de este valor se confinaba a los empleados, y que fuera de ahí los empresarios responsabilizaban al Estado (Camp, 1990, pp. 43 y ss.). 
Por su parte, el estudio de Anselmo García y sus colaboradores hecho en 1995, durante el auge del discurso de una nueva cultura empresarial ${ }^{14}$ y de la calidad, tiene puntos de coincidencia con la investigación de Alba. Para estos autores, la cultura productiva en México es una de tipo excluyente, enfatizada en

[...] modelos de organización, símbolos de autoridad, actitudes de mandar-obedecer, así como costumbres y hábitos de exclusión de los trabajadores para mejorar en la empresa. Se les ha excluido también de la construcción de las decisiones, y se han subvalorado a veces $\sin$ analizar sus cualidades humanas y profesionales que podrían enriquecer la gestión del proceso productivo [...] (García, Hernández y Wilde, 1995).

Los autores enlistan una serie de apreciaciones que van desde la perspectiva de la propia empresa hacia sí misma, sus trabajadores y los sindicatos; de los trabajadores sobre ellos y sobre su empresa; y de los sindicatos acerca de la empresa y su rol en ella. ${ }^{15}$

Otros trabajos, como los de Rafael Montesinos (1995, 2009), se enfocan en la conducta y mentalidad empresarial en México, pero sus análisis quedan en una retórica acusatoria de lo que el autor llama "la conducta oligárquica" de los empresarios, acostumbrados al paternalismo, la corrupción

14. Para estos autores, la cultura de la productividad en México comprende el origen y desarrollo de las características de "la cultura como resultado de la interacción de individuos en un colectivo con el objeto de producir, es decir, alcanzar objetos económicos y sociales, sumados a una serie de herramientas técnicas y administrativas en un centro de producción" (García, Hernández y Wilde, 1995). 15. Vale la pena resaltar aquí unas cuantas de estas apreciaciones: I) la empresa se percibe como un sistema cerrado en abierto rechazo a la influencia de los trabajadores y del sindicato; 2) paradójicamente el eje del entendimiento es la desconfianza expresada en un rígido control sobre las tareas y actitudes del trabajador: el trabajador percibe que no se le contrata para pensar, sino sólo para obedecer, ejecutar y repetir, y no para innovar; 3) el sindicato se percibe como un sistema cerrado en abierto rechazo a la influencia de la empresa; 4) se percibe que la administración de la producción es del dominio exclusivo de la empresa (García, Hernández y Wilde, 1995). 
y los "negocios de saliva", ${ }^{16}$ así como a su desprecio a la clase trabajadora (1995, pp. 105-106). Si bien sus trabajos dan seguimiento a los discursos de los empresarios y sus corporaciones, no se busca en ellos una imbricación entre el comportamiento de los empresarios y el poder político, como tampoco se recurre a la técnica de la entrevista con miembros de este sector.

En todo caso, estos estudios sobre cultura empresarial o cultura de la productividad, si bien evidencian un modo de ser del empresariado y del trabajador, son análisis que se han confinado sólo a esa dimensión, sin encontrar las posibles soluciones a los problemas que plantean, como el de la productividad, relacionados con aspectos estructurales y de relaciones de poder entre el Estado y los empresarios.

\section{Consideraciones finales para una agenda de investigación}

Esta revisión de la literatura tuvo como trasfondo una preocupación sociológica por la desigualdad e injusticia social endémica de México. En este punto, y durante la consulta de varios trabajos, llama la atención que pocas veces se hace alusión a la percepción de las élites del poder respecto a esta problemática, y que menos aún se planteen trabajos de investigación, salvo en contados casos y de alcance limitado.

Si en general el estudio de las élites políticas y económicas requiere siempre de ser contextualizado, el conocimiento de estas en el caso mexicano es una condición sine qua non para entender el proceso que las constituye como élites del poder en un momento histórico determinado. Estudiar a las élites en su contexto puede contribuir a entender el modo

16. Esta es una frase usada por Montesinos para referir a una retórica falsa, vacua, o al discurso de los que no dicen nada. 
en que se ejerce el poder (de ambas élites) y el impacto que este tiene en el resto de la sociedad.

Aun con el esfuerzo que supuso el trabajo de esos años, la discusión o conocimiento de lo que ocurría en otras academias, principalmente en la anglosajona -que fue la más prolífica-, no se refleja en la literatura. De ahí que, como señalaron algunos autores citados, escasee la teoría o rigor en la definición de los conceptos que se emplean. Tal vez esto mismo provocó que no se dieran pasos hacia la elaboración de teorías de alcance medio que pusieran límites a la proliferación de estudios globalizados, los cuales marcaron la agenda de lo que se debía estudiar y que, lo que más preocupa, suelen imponer explicaciones a problemas contextualmente diferentes. De esto mismo se desprendió la multiplicación en los años abordados, y no sólo en México, de estudios sobre los empresarios, destacándoseles, sin quererlo o no, como los actores centrales de la globalización frente al Estado y el resto de la sociedad, ángulo que curiosamente coincide con uno de los objetivos centrales de la ideología neoliberal.

Se considera también que en la literatura explorada se dio una concentración, al menos en los años citados, de los estudios sobre las acciones corporativas y políticas del empresariado en detrimento del estudio de la clase política. Asimismo, se observa que gran parte de los estudios sobre empresarios fueron atrapados por el dinamismo de los cambios desde que México entró al Acuerdo General sobre Aranceles Aduaneros y Comercio (GATT, por sus siglas en inglés), en 1985, hasta la firma del Tratado de Libre Comercio, en 1994, así como por el propio discurso de la globalización que marcó el sendero de lo que era importante investigar. Estas circunstancias fueron también las que propiciaron un recambio en el paradigma predominante en la academia hasta los años 70 . 
En otras academias del mundo se investiga sobre las ideas y valores de las élites respecto a temas como pobreza, equidad y desarrollo. Si bien en México de manera profusa se han analizado las características del sistema político, del régimen político y de la clase política, así como su interacción con el poder económico, queda como una tarea pendiente enfocarse a los efectos que la estructura de poder de un periodo determinado arroja sobre las condiciones socioeconómicas de su sociedad.

Alba, C. (2006). "Los empresarios y la democracia en Bibliografía México”. Foro Internacional, XLVI( I83), I22-I 49.

Alonso,J. (1976). La dialéctica clases-élites en México. México: Ediciones La Casa Chata.

Babb, S. (200I).Managing Mexico:Economists. From Nationalism to Liberalism. Princeton: Princeton University Press. (2003). Proyecto México. Los economistas del nacionalismo al neoliberalismo. México: Fondo de Cultura Económica.

Brandenburg, F.R. (1964). The Making of Modern Mexico. New Jersey: Prentice-Hall.

Camp, R. A. (1990). Los empresarios y la política en México. México: FCE. (2006). Las élites del poder en México. Perfil de una élite del poder para el siglo XXI. México: Siglo XXI.

Carrión, J., y Aguilar Monteverde, A. (1977). La burguesía, la oligarquía y el Estado. México: Nuestro Tiempo.

Centeno, M. A. (1994). Democracy within Reason. Pennsylvania: Pennsylvania State University Press.

Concheiro, E., Fragoso,J. M.,y Gutiérrez, A. ( 1979). El poder de la gran burguesía. México: Ediciones de Cultura Popular. Crespo, J. A. (1997). "Los estudios electorales en México en el contexto del cambio político". CIDE (documento de trabajo). Recuperado de:http://aleph.academica.mx/ jspui/handle/56789/4973 
Bibliografía
Dahl,A. R. (196I). Who Governs? Democracy and Power in an American City. New Heaven: Yale University Press.

De la Cruz Carrillo, O. (20I2). “La designación de los consejeros electorales en 20I0. Entre la autonomía y las cuotas partidarias". Revista de Ciencias Sociales y Humanidades, (73), I27-I48.

Derossi, F. (1978). El empresariado mexicano. México: UNAM, IIS.

Domhoff,W. (1983). Who Rules America Now? A view for the 80s. Englewoog Cliffs: Prentince Hall.

y Dye, T. (1987). Power Elites and Organizations. Newbury Park: Sage Publications.

García, A., Hernández, A., y Wilde, R. (1995). “Cultura productiva/cultura improductiva: los retos en el centro de producción”. El Cotidiano, 12(73). Recuperado de: http:// www.elcotidianoenlinea.com.mx/articulo.asp?id_articulo $=|44|$

González Casanova, P. (1965). La democracia en México. México: Ediciones Era.

Gruber,W., et al. (197I). “Carrer Patterns of Mexico's Political Élite”. Western Political Quarterly, 24, 467-482.

Hamilton, N. (1983). Los límites de la autonomía del Estado. México: Editorial Era.

Hernández Romo, M. (2004). La cultura empresarial en México. México: Universidad Autónoma de Aguascalientes, $\mathrm{H}$. Cámara de Diputados Legislatura LIX, Miguel Ángel Porrúa.

(2007). "Balance de los estudios de cultura empresarial en México”, en J. Basave, y M. Hernández (eds.), Los estudios de empresarios y empresas. Una perspectiva internacional (PP. 2II-235). México: UNAM, UAM, Plaza y Valdés.

Hoyos, J. L. (1973). “Grupos empresariales: dominación y hegemonía”, en C. Sirvent, S. Colmenero, et al. (eds.), 
Las clases dirigentes en México (pp. 89-109). México: Bibliografía FCPYS, UNAM.

Krieger, E. (1990). “Derecho electoral en julio de 1988”, en P. González Casanova (coord.), México el 6 de julio de 1988. Segundo informe sobre la democracia (pp. 14-49). México: Siglo XXI.

Labastida, J. (1980). "Los grupos dominantes frente a las alternativas de cambio", en AA.VV., El perfil de México en 1980, vol. 3 (pp. I00-164). México: Siglo XXI.

Lindau, J.D. (1993). Los tecnócratas y la élite gobernante mexicana. México: Joaquín Mortiz.

Luna, M., y Puga, G. (2006). “Los estudios sobre los empresarios y la política. Recuento histórico, líneas de investigación y perspectivas analíticas". V Congreso Nacional AMET. Recuperado de: http://www.iztapalapa.uam.mx/ amet/vcongreso/webamet/indicedemesa/ponencias/ Mesa\%202I/Pugasm I0.pdf

Meyer, L. (1998a).“Mexico: Economic Liberalism in an Authoritarian Polity", en J. Lindau, y T. Cheek (eds.), Markets Economics and Political Change: Comparing China and Mexico (pp. I27-I57). Maryland: Rowman and Littlefield Publishers.

(1998b). Fin de régimen y democracia incipiente en México. Hacia el siglo XXI. México: Océano.

Millán, R. (1988). Los empresarios ante el estado y la sociedad. México: UNAM, Siglo XXI.

Mills, C.W. (1987). La élite del poder. México: Fondo de Cultura Económica.

Montesinos, R. (1995). "Mitos y miserias de la cultura empresarial”. El Cotidiano, (73). Recuperado de: http:// www.elcotidianoenlinea.com.mx/articulo.asp?id_articulo $=2686$ (2009). "Empresarios: la construcción de un sujeto social. 25 años de seguimiento e interpretación”. El Cotidiano, (I56), 203-2I7. 
Bibliografía
Needleman, C., Needleman, M., et al. (1969). "Who Rules Mexico. A Critique of Some Current Views on the Mexican Political Process". Journal of Politics, 3 I, I0 I I1034.

O’Donnell, G., y Schmitter, P. (1994). Transiciones desde un gobierno autoritario.Vol. Iv. Conclusiones tentativas sobre las democracias inciertas. Barcelona: Paidós.

Padget, V. A. (1966). The Mexican Political System. Boston: Houghton Co.

Poulantzas, N. (1998). Poder político y clases sociales en el estado capitalista. México: Siglo XXI Editores.

Pulido Jiménez, M. (20I4). “¿Para eso queríamos el nuevo IFAI?”. El Universal. Recuperado de: http://www.eluniversalmas.com.mx/editoriales/20 I4/08/7 I836.php

Rousseau, I. (1998). "La SPP y la dinámica de constitución de un equipo: 1982-1988”. Foro Internacional, 38(2/3), 302-339.

Scott, J. (1990). The Sociology of Elites. Cheltenham: Edward Elgar Publishing.

- (2008)."Modes of Power and the re-conceptualization of elites". The Sociological Review. Monograph Series, 56(I), 25-43.

Starr, P. K. (1999). “Monetary Mismanagement and Inadvertent Democratization in Technocratic Mexico". Studies in Comparative International Development, (winter), 35-65. Story, D. (1986). Industry, the State and Public Policy in Mexico. Austin: University of Texas Press.

Suárez, F. (I99I). Élite, tecnocracia y movilidad política en México. México: UAM-X Colección Ensayos.

Tannenbaum, F. (1968). Mexico: The Struggle for Peace and Bread. Nueva York:Alfred A. Knopf Inc.

Teichman,J. (1996). Privatization and Political Change in Mexico. Pittsburgh: Pittsburgh University Press. 
(200I). The Politics of Freeing Markets in Latin America:

Bibliografía Chile, Argentina and Mexico. Chapell Hill:The University of North Caroline Press.

Tirado, R. (2004). Los industriales, la política y el fin del proteccionismo industrial (tesis de doctorado inédita). UNAM: México.

(20I2). "Las élites de América del Norte en los orígenes del TLC", en A. Salas Porras, y K. Valverde (coords.), ¿Quién gobierna América del Norte? (pp. 3 I-76). México: UNAM.

Tucker, W. P. (1957). The Mexican Government Today. Minneapolis: University of Minnesota Press.

Valdés Ugalde, F. (1997). Autonomía y legitimidad. Los empresarios, la política y el Estado en México. México: Siglo XXI. 